2016-07

The estimation of minimum efficient scale of the port industry

Seo, Y-J

http://hdl.handle.net/10026.1/4592

10.1016/j.tranpol.2016.04.012

Transport Policy

All content in PEARL is protected by copyright law. Author manuscripts are made available in accordance with publisher policies. Please cite only the published version using the details provided on the item record or document. In the absence of an open licence (e.g. Creative Commons), permissions for further reuse of content should be sought from the publisher or author. 


\title{
The estimation of minimum efficient scale of the port industry
}

\begin{abstract}
Terminal scale has been the subject of discrete episodes of hotly contested policy debates. From the perspective of port authorities or governments, knowing the Minimum Efficient Scale (MES) is salient, because they sometimes determine the port development or expansion based on the port capacity or the existing size of the terminal. Notwithstanding the importance of knowing the exact MES, extant literature has not managed to estimate MES in the port industry. This study aims to estimate the MES in the port industry in South Korea in order to identify whether Container Terminal Operators (CTOs) are under economies of scale, constant economies of scale or diseconomies of scale; we explore a bottom point of the average cost curve in order to suggest an adequate scale for the port industry in Korea. The finding demonstrates that undercapacity may be a strong issue in Korean container ports. However, CTOs in Busan port are in an overcapacity area given the market demand of container throughput in 2013, which is approximately 25 times larger than the estimated MES; in fact, all CTOs in Busan port operate at more than $20 \%$ of MES. This study then can provide port policy makers with a helpful tool to derive ex-ante MES level at the terminal designing stage and to adjust ex-post port investment decisions at the additional port capacity designing stage, which may contribute to avoiding overcapacity.
\end{abstract}

Keywords: MES; overcapacity ; port; container terminal; port capacity

\section{Introduction}

Rapid port development in North-East Asia which sought to dominate the market ahead of adjacent countries and achieve hub-port status has triggered severe competition between container ports. Although South Korea (hereafter Korea) has played a crucial role in the international shipping and port industry as an economy that handled the fourth largest global container port throughput of approximately 23 million TEU in 2013 and owned the fifth largest fleet in terms of dead weight tonnage with leading container shipping lines such as Hanjin shipping and Hyundai Merchant Marine and the second largest shipbuilding industry globally (UNCTAD, 2014), Container Terminal Operators (CTOs) particularly in Korea have suffered overcapacity problems which are unprecedented (Korea Shipping Gazette, 2014). This has devastated CTOs' financial status, since a number of factors such as the increased bargaining power of shipping lines stemming from mergers and acquisitions, strategic alliances amongst major shipping lines, withdrawal of sales from particular CTOs, and new entrants into existing ports have had a negative impact on container terminal markets overall. As a result, the terminal handling charge per TEU in ports was significantly less than in both China and Japan (Korea Shipping Gazette, 2013). This causes a loss of profits and an outflow of national wealth from Korea's viewpoint.

Terminal scale has been the subject of discrete episodes of hotly contested policy debates (Asteris and Collins, 2010). From the perspective of economic theories, CTOs should be keen on a scale that is equivalent to the minimum efficient scale (MES), which is defined as the long-run output where the internal economics of scale have been fully exploited (Kaselimi et al., 2011). CTOs are essentially interested in identifying the terminal scale in order to enter the market and compete with other CTOs, although the scale may vary according to locations with 
different costs (Kaselimi et al., 2011). From the perspective of port authorities or governments, knowing the MES is vital, because they sometimes determine the way in which existing assets should be subdivided for port concession. In addition, they may utilise this information regarding the MES, when they plan to develop new ports based on the port capacity or the existing size of the terminal. Central or regional governments or port authorities have strived for the optimal port capacity, because it is directly connected to both national and regional economics as an economic springboard (Tongzon and Heng, 2007; Bottasso et al., 2013; Deng et al., 2013; Song and van Geenhuizen, 2014; Chang et al., 2014; Park and Seo, 2016). Underestimation of port capacity results in constructing too many berths and equipment, whereas the overestimation leads to vessel congestion (Chang et al., 2012). For example, if the CTO pursues $100 \%$ berth utilisation, it can minimise its costs per ship for ship owners, but it generates costs due to waiting for berth (De Weille and Rai, 1974). Also, if the CTOs construct and operate many berths to minimise the vessels' waiting time, they have to face high costs of constructing and operating the berths (De Weille and Rai, 1974). In fact, the relationship between the port capacity and waiting time is a trade-off. In this regard, Jansson and Shneerson (1982) pointed out that the decisions on port investment should be in concert with the long-run total cost, incorporating port development costs and waiting costs of ships and cargo. Identifying the optimum port capacity is not easy, because it is required to reflect multiple perspectives of related players (e.g. ship owners and CTOs). This sometimes results in compromised port capacity rather than the optimum one. Accordingly, various stakeholders seek awareness of when the market becomes sufficiently large for the new terminal construction in the same ports via the estimation of the MES (Kaselimi et al., 2011).

The estimation of MES for the service sector such as sea transport, aviation, travel, insurance, and land transport is rare owing to the difficulty of making such estimates, and MES for the service sector is likely to be lower than the manufacturing sector (Pratten, 1988). In the port context, some extant studies investigate the concept of 'global optimum size' of a terminal or a notion of critical mass of the container terminal (Musso et al., 1999; Wiegmans et al., 2009). Interestingly, Kaselimi et al. (2011) have attempted to identify the preferred scale of the container terminals, but they failed to find solutions due to different port governance, market size, structure and operational considerations. Surprisingly, notwithstanding the importance of knowing the exact MES (Theys et al., 2010; De Langen and Pallis, 2006), extant literature has not managed to estimate the MES in the port industry. A paucity of extant works on the MES in the port stimulated this study. Therefore, bearing in mind this research gap, the main purpose of this study is to estimate the MES in the port industry in Korea in order to identify whether CTOs are under economies of scale, constant economies of scale or diseconomies of scale so that we can explore a bottom point of the average cost curve. By doing so, this study can provide port planners and port policy makers with a helpful tool to derive ex-ante MES level at the terminal designing stage and to adjust ex-post port investment decisions at the additional port capacity designing stage, which may contribute to mitigating overcapacity. This study deals with the real issues in Korea, but the approach of this study might be applied to other regions of the world that suffer overcapacity issues (e.g. port of Colombo in Sri Lanka, see Galhena, 2015).

Section 2 reviews the literature on overcapacity and the MES. Section 3 explains the main methodology this study employed. Section 4 presents the results. Finally, the research implication and conclusions are drawn in section 5. 


\section{Literature review}

\subsection{The overcapacity issues and MES}

Traditionally, industrial organisations have been concerned with the optimum firm size and industrial plant capacity in order to minimise costs and maximise profits. Market structure is generally categorised into perfect competition, oligopoly, duopoly and monopoly. Such a structure is determined by the number of firms within the industry, the distribution of the firm size, product differentiation and entry condition. Amongst them, the number of firms may be a major determinant for the industry's structural characteristics such as monopoly and perfect competition. Also, entry barrier, minimum capital for optimum scale and MES affect the market structure. In the area of industrial organisation the MES concept is of paramount importance, because large MES can significantly reduce unit cost and might cause high concentration and significant entry barriers (Caves et al., 1975; Cory, 1981). In this paper, the main focus lies in capacity issues as well as MES.

Overcapacity occurs due to the misallocation of resources and a situation where superfluous infrastructure exists (Barzdukas et al., 2000). Haralambides (2002) pointed out that higher competition may bring a greater need for overcapacity of ports, and highlighted that the competition and overcapacity mix is an explosive cocktail. The advent of containerisation forces ports to remain capital-intensive and make tremendous investment in both port infrastructure and container handling equipment. Furthermore, the long life of terminals, capital indivisibilities, shipping liners' interest in minimising ship waiting time, economies of scale in port construction and the optimism of port planners may be attributed to the risk of excess capacity of ports (Haralambides, 2002; Heaver, 1995).

According to Porter (1998), expanding capacity is the most important strategic decision confronting firms in terms of the capital and the complexity of the decision-making problem since capacity adding requires lead times for years and capacity persists for a long time. Therefore, thorough expectations such as future demands and competitor's future behaviour should be made before capacity expansion. There would be hostile consequences if a large number of competitors participate in expanding capacity. It is worth noting here that unlike a manufacturing sector which is able to produce for the future and manage capacity and demand by storing the products, transport service industries such as port, shipping, airline and rail are likely to face capacity issues due to the fact that the services they offer are not storable (De Weille and Rai, 1974). In most container ports in Korea, terminal markets seem to be oligopoly (Korea Shipping Gazette, 2013), in which CTOs are mutually inter-dependent. Each CTO strategic movement is centred on enhancing market share, while avoiding overcapacity. In general, ports decide to expand their facilities based on an expectation of a future cargo throughput, and internally-driven and customer-compelled strategies of each terminal may result in excessive duplication and overcapacity (Slack, 1993). Overcapacity would result in inefficient use of port infrastructure (Chang et al., 2012). In the port sector, there always exists a conflict between monopoly power and concern for excess capacity (Heaver, 1995). Monopoly tends to hinder innovation and efficiency while overcapacity results in inefficiencies due to superfluous duplication, which wastes high capital investment (Barzdukas et al., 2000). 
Knowing the MES would play a vital role in providing the most efficient and effective service at a minimum cost (Chang et al., 2012), especially when CTOs are likely to provide homogenous service and compete based on the cost reduction. In terms of differentiation, CTOs tend to provide homogeneous services: the transfer of boxes between ship and ashore (Ashar, 2001). The fact that services are not differentiated makes cost reduction important to their competition. The overcapacity problem often occurs when competitors aim at preemptive behaviour in pursuit of a cost advantage and the MES because larger plants are likely to be more efficient than smaller plants. The MES of a container terminal is defined as "the smallest scale at which output can be produced at minimum average long run cost" (Kaselimi et al., 2011, p. 72). If the MES of a current CTO is large compared with the market size, potential or new entrants may encounter competitive disadvantage owing to a smaller scale or need for building a similar capacity to that of the CTO (De Langen and Pallis, 2007). This may lead both of them to the possibility of price war and profit loss because of the considerable excess supply (De Langen and Pallis, 2007).

\subsection{Overcapacity issues: the case of ports in Korea}

Recently, very low container cargo handling fees have been a controversial issue in Korea due to overcapacity (Korea Shipping Gazette, 2014). Busan port, the largest container port in Korea aims to become a major hub port in North-East Asia by building and developing New port from 2006 up to now under the base of North port. When allowing new entrants into the port, policy should be very careful regarding creating conditions that allow entry without directly hindering the survival and growth of incumbents (De Langen and Pallis, 2007). Unfortunately, many CTOs in Korea have suffered overcapacity problems derived from the Korean government's expanding plans based on too optimistic forecasts (Korea Shipping Gazette, 2013). This decision to expand container ports on a large scale has led to overcapacity. After a number of new CTOs entered the port market, they have sought to occupy cargoes. Market entry was too rapid and easy due to government support, even though this adding capacity in large lumps should be carried out with caution. As a result, they have started to compete with each other based on price reduction to capture more cargoes and shipping lines, although when changing the port price they should be extremely careful (Gardner et al., 2006). This drastically exacerbates the CTO's margin. According to a game theoretic approach, it is not likely that the outcomes of price war lead to a predatory situation if entry barriers are not significant (Flor and Defilippi, 2003). Even if the CTO temporarily reduces the price below its cost, it would be unable to recover its losses even after eliminating competition, since price increase may foster the entry of new players (Flor and Defilippi, 2003). In reality, however, some CTOs in Busan port tend to be myopic, so they simply start to reduce the price without allowing for a competitor's response. Since 2011, container cargo throughput has been tied up while the supply of terminal facilities has gradually increased. It causes an imbalance between demand and supply. In turn, CTOs were about to lower their price at break-even point in 2013 (Korea Shipping Gazette, 2014). The main reasons for the overcapacity stemmed from incorrect forecast of port demand. Busan New port has been initiated based on this forecast, since demand for Busan port is expected to increase in the long-term perspective. However, this forecast does not fit real demands for terminal facilities, so overcapacity problems occur. Prior to the Busan New port construction, insightfully, a report from OECD (2004) warned that the rush towards the costly building of mega container ports may lead to the pitfall of 
overinvestment, and pointed out that such a rush for ever heavier investment is lucrative only when economic growth remains strong.

In 2013, the container handling fee per TEU in Busan port approximately cost \$45-50, significantly less than in both Shanghai port (\$80-90) in China and Tokyo port (\$160-180) in Japan (Korea Shipping Gazette, 2013). This handling fee in Busan port is equivalent to that of $1 / 8$ of LA port in USA and 2/3 of Kaohsiung port in Taiwan. Of course, CTOs are interested in reducing or stabilising the container handling fee as long as they can maximise the profits (Bassan, 2007). High price may simply guide the port to extinction while low prices may attract customers but investment costs may not be recovered in the long-run (Haralambides, 2002).

The aforementioned overcapacity issues in the ports of Korea and the fact that quantitative approaches to the determination of MES remain hugely untouched territory, where most port economists have approached this issue to a limited extent and mostly in a qualitative manner (Theys et al., 2010), stimulate the current study.

\section{Methodology}

\subsection{Finding $M E S$}

As firms start producing output such as goods, services or throughput in the case of CTOs, they will initially face increasing returns to scale (RTS). In other words, they can obtain a proportionally larger amount of output than the increase in inputs. Consequently, their average costs will decline with more output, which is called economies of scale. However, if the firms increase production further until economies of scale are exploited, increasing RTS will eventually turn into constant and then decreasing RTS where only proportionally smaller output is generated given the same increase in input. Concurrently, average costs will decrease, hit a minimum and then start going up. This change corresponds with a U-shaped total average cost curve that is commonly used in economics.

The MES is technically defined as the optimal amount of production that minimises total average cost. It can be found at the minimum point of the average cost (AC) function. On the other hand, the MES can be also derived using the RTS function. This is because the minimum point of the AC function is located where increasing RTS (RTS >1) changes to decreasing RTS (RTS $<1)$. That is, the MES occurs where RTS is 1. Zellner and Revankar (1969) first introduced the method of finding MES using the RTS function based on the generalised production function and then Zellner and Ryu (1998) elaborated the method by additionally deriving the AC function from the RTS function. Our study follows their method as explained below.

\subsection{The production function to the RTS function}

Suppose a generic production function

$$
f=f(K, L)
$$


where $\mathrm{f}$ is a homogeneous function of degree $\mu, K$ and $L$ are factors of production and $\frac{d f}{d K}>0$ and $\frac{d f}{d L}>0 . K$ and $L$ commonly represent the amount of capital and labour, but any main factors of production can be used for this purpose.

The monotonic transformation of $f$ yields a homothetic production function $(\mathrm{y})$, which is defined as a generalised production function (Zellner and Revankar, 1969).

$$
y=y(f)
$$

where $y=0$ if $f=0$ and $\frac{d y}{d f}>0$. The main property of a homothetic production function is that marginal rate of technical substitution between $K$ and $L$ is homogenous of degree zero, i.e. it does not depend on the proportional increase of the factors of production.

Then, the RTS function is defined as Zellner and Ryu (1998).

$$
\alpha(y)=\alpha(d y / y) /(d f / f)
$$

where $\alpha$ is a scale parameter which is also an initial value of RTS at $y=0$.

Its functional form can be specified following Zeller and Ryu (1998).

$$
\alpha(y)=\alpha /(1+\theta y)
$$

If $\theta>0$, RTS decreases as y goes up, but it increases if $\theta<0$.

\subsection{MES and the average cost (AC) function}

Rearrange the RTS function (4) for $y$,

$$
y=(\alpha-\alpha(y)) / \alpha(y) \theta
$$

The average cost minimising production level, i.e. the minimum efficient scale (MES), is found where RTS is 1 . Thus, the value of the MES is:

$$
y^{*}=(\alpha-1) / \theta
$$

On the other hand, the RTS function is alternatively defined as:

$$
\alpha(y)=A C(y) / M C(y)
$$

where $\mathrm{AC}(\mathrm{y})$ is an average cost function and $\mathrm{MC}(\mathrm{y})$ is a marginal cost function. Since a total cost (TC) function is defined in terms of an average cost function as $\mathrm{TC}(\mathrm{y})=y \mathrm{AC}(y)$, solving the optimisation problem of the total cost function yields ${ }^{1}$ :

$$
\ln T C(y)=c+\int(1 / \alpha(y) y) d y
$$

where $\mathrm{c}$ is the constant of integration.

\footnotetext{
${ }^{1}$ See Zellner and Ryu (1998) for technical details.
} 
Then, using the specified RTS function in (4) and solving the above equation, the average cost (AC) function can be fully derived.

$$
\ln A C=\ln (c)+((1-\alpha) \ln y+\theta y) / \alpha
$$

\subsection{Estimation method}

Substitute (4) for $\alpha(y)$ in (3) and solve the differential equation.

$$
\ln y+\theta y=\ln f
$$

Now substitute a Cobb-Douglas production function $f(K, L)=\gamma K^{\alpha(1-\delta)} L^{\alpha \delta}$ for $f$.

$$
\ln y+\theta y=\ln \gamma+\alpha(1-\delta) \ln K+\alpha \delta \ln L
$$

where $\alpha$ is a scale parameter as defined above and $\delta$ is a weight parameter.

Assuming an identically and independently distributed error term that follows a normal distribution, the log likelihood (LL) function of (11) can be derived.

$$
\begin{aligned}
L L=c^{\prime}+(N / 2) & \ln \left[\sum_{i=1}^{N}\{\ln y+\theta y-\ln \gamma-\alpha(1-\delta) \ln K-\alpha \delta \ln L\}^{2}\right] \\
& +\sum_{i=1}^{N} \ln (1+\theta y)
\end{aligned}
$$

where $N$ is observation size, $i$ is an observation index and $c$ ' is a constant

The individual contribution $(l l)$ is:

$$
\begin{gathered}
l l=-(1 / 2) \ln \sigma^{2}-\left(1 / 2 \sigma^{2}\right)\{\ln y+\theta y-\ln \gamma-\alpha(1-\delta) \ln K-\alpha \delta \ln L\}^{2} \\
+\ln (1+\theta y)
\end{gathered}
$$

Then, the numerical optimisation in the Maximum Likelihood Estimation (MLE) method can estimate the unknown parameters, $\sigma, \theta, \alpha$ and $\delta$. We use Marquardt algorithm (Marquardt, 1963) for this study. The value of $\alpha$ is obtained by adding two coefficient estimates $(\alpha=\alpha(1-\delta)+\alpha \delta)$ and the value of $\delta$ is subsequently obtained by dividing $\alpha \delta$ by $\alpha$. Finally, the AC function and the MES value can be obtained as outlined in (6) and (9).

\subsection{Data}

The sample used in this study consists of 24 CTOs in ten Korean ports, which covered95.8\% of total throughput of Korea in 2013. The data are combined from Data Analysis, Retrieval and Transfer (DART) System of Financial Supervisory Service (FSS) of the Korean government, Korea Port Logistics Association (KPLA), the Korea Chamber of Commerce and Industry (KCCI), the website of port authorities, website of each Regional Oceans \& Fisheries Administration (ROFA), the website of Shipping and Port Integrated Data Centre (SP-IDC) and website of each CTO. The list of the CTOs is reported in Table 1. 


\section{Table 1}

The list of CTOs.

\begin{tabular}{|c|c|c|c|c|c|}
\hline ID & Port & Container Terminal & Operator & TEU & Profits \\
\hline 1 & Busan & Jaseong & Hutchison Korea Terminals & $1,366,534$ & $-10,549,262,685$ \\
\hline 2 & & Sinseon & CJ Korea Express Busan Container Terminal & $1,744,861$ & $-41,678,629,041$ \\
\hline 3 & & Gamman & Sebang Busan Container Terminal & $1,465,206$ & $-12,731,361,643$ \\
\hline 4 & & Shin Gamman & Dongbu Busan Container Terminal & $1,032,732$ & $2,632,449,513$ \\
\hline 5 & & New Port 1 & Pusan New Port International Terminal & $1,747,307$ & $-5,191,638,049$ \\
\hline 6 & & New Port 2 & Busan New Port & $3,299,457$ & $35,726,290,824$ \\
\hline 7 & & New Port 3 & Hanjin New Port & $2,375,614$ & $21,945,464,049$ \\
\hline 8 & & New Port 4 & Hyundai Busan Newport Terminal & $2,391,890$ & $18,176,946,309$ \\
\hline 9 & & New Port 5 & BNCT & $1,099,366$ & $-79,328,321,784$ \\
\hline 10 & Gwangyang & Port 2-1 & Hanjin Shipping Gwangyang Terminal & 634,916 & $-33,000,000$ \\
\hline 11 & & Port 2-2 & Korea International Terminal & 747,445 & $325,974,235$ \\
\hline 12 & & Port 3-1 & Gwangyang West Containter Terminal & 902,077 & $76,000,000$ \\
\hline 13 & Incheon & ICT & Incheon Container Terminal & 592,662 & $7,022,397,041$ \\
\hline 14 & & SICT & Sunkwang & 237,800 & $107,000,000$ \\
\hline 15 & & Korea Express & CJ Korea Express & 400,870 & $-539,102,405$ \\
\hline 16 & PyeongTaek & East Port & Pyeongtaek Container Terminal & 285,906 & $815,152,455$ \\
\hline 17 & & East Port & Pyeongtaek Dongbang I-Port & 85,772 & $-12,576,541,611$ \\
\hline 18 & Ulsan & Newport & Ulsan Dongbang I-Port & 239,018 & $-9,622,001,489$ \\
\hline 19 & & JCT & Jeongil Ulsna Container Terminal & 145,538 & $414,245,562$ \\
\hline 20 & Mokpo & Newport & Mokpo Newport & 93,920 & $-3,956,695,064$ \\
\hline 21 & Pohang & Yeongil Newport & Pohang Yeongil Newport & 114,649 & $-8,982,167,733$ \\
\hline 22 & Masan & Port 4 & Masan Port 4 Operation & 6,451 & $-132,000,000$ \\
\hline 23 & Daesan & Port 1 & Daesan Port Operation & 63,739 & $-8,982,167,733$ \\
\hline 24 & Kyeongin & Incheon Terminal & Hanjin Shipping & 28,000 & \\
\hline
\end{tabular}

Note: TEU represents annual throughput in 2013. Profits are annual profits in 2013 and denoted in Korean Won.

Source: Compiled by Authors from Data Analysis, Retrieval and Transfer (DART) System of Financial Supervisory Service (FSS) of the Korean government, Korea Port Logistics Association (KPLA), the Korea Chamber of Commerce and Industry (KCCI), the website of port authorities, website of each Regional Oceans \& Fisheries Administration (ROFA), the website of Shipping and Port Integrated Data Centre (SP-IDC) and website of each CTO. 
The main business of the CTOs can be considered as generating throughput using their facilities and labour force. Therefore, their throughput (TEU) can be defined as production (y), which is a function of the amount of non-current or fixed assets $(\mathrm{K})$ and the size of workforce (L) as in (11).

The data of the CTOs are retrieved from the balance sheets and the profit and loss accounts of their 2013 annual reports. Initially, we compare two model specifications before presenting the final model. The first model (Model 1) uses non-current assets as K, which includes property, plant and equipment, intangible assets and other long-term investments. Its sample size is 20 . Four CTOs (ID 12, 13, 23 and 24) are excluded since the size of the workforce is not reported. On the other hand, non-current assets may include assets that are not critical in port operation, so we also test an alternative model (Model 2). It uses a narrower term, fixed (or tangible) assets, which include only property, plant and equipment. Model 2 uses 17 CTOs that additionally excludes CTO ID 10, 14, and 22 as they do not report fixed assets separately in their annual reports.

\section{Results}

The generalised production function in (11) is estimated by the Maximum Likelihood Estimation (MLE) method as described in the methodology section. The estimation results of both models are presented in Table 2.

Table 2

Estimation results.

Model 1: Non-current assets and workforce

\begin{tabular}{|c|c|c|c|c|c|}
\hline Coefficients & & $\theta$ & $\alpha(1-\delta)$ & $\alpha \delta$ & constant \\
\hline Estimates & & 0.0000 & 0.1218 & 1.6200 & 2.8150 \\
\hline Standard errors & & 0.0000 & 0.0703 & 0.3437 & 2.3130 \\
\hline \multirow[t]{2}{*}{$p$-value } & & 0.0987 & 0.0832 & 0.0000 & 0.2236 \\
\hline & $\alpha$ & 1.7418 & $\delta$ & 0.9301 & 20 \\
\hline Log Likelihood & & -0.0575 & & SIC & 0.7547 \\
\hline
\end{tabular}

Model 2: fixed assets and workforce

\begin{tabular}{|c|c|c|c|c|c|}
\hline Coefficients & & $\theta$ & $\alpha(1-\delta)$ & $\alpha \delta$ & constant \\
\hline Estimates & & 0.0000 & 0.1994 & 0.9811 & 3.6440 \\
\hline Standard errors & & 0.0000 & 0.1508 & 0.2750 & 4.2387 \\
\hline \multirow[t]{2}{*}{$p$-value } & & 0.6835 & 0.1861 & 0.0004 & 0.3900 \\
\hline & $\alpha$ & 1.1805 & $\delta$ & 0.8311 & 17 \\
\hline Log Likelihood & & 5.3308 & & SIC & 0.2061 \\
\hline
\end{tabular}

Note: $\alpha(1-\delta)$ is the coefficient of $\operatorname{lnK}$ and $\alpha \delta$ is the coefficient of $\operatorname{lnL} . \mathrm{p}$-value is probability value for the null hypothesis that the coefficient is zero. $\mathrm{n}$ is sample size. SIC is Schwarz Information Criteria and AIC is Akaike Information Criteria. 
The size of workforce (L) significantly and positively affects the amount of throughput in both models as the coefficients, $\alpha \delta$, indicate. That is, the larger workforce leads to more TEU processed. It is consistent with what is usually expected from container port operation. The weight of workforce $(\delta)$ in producing throughput is also large. On the other hand, the importance of non-current or fixed assets $(\mathrm{K})$ is relatively weak in both estimation results and only significant in Model 1. When two models are compared in terms of their explaining power, Model 1 seems to be a stronger model in terms of the significance of individual coefficients and the higher values of information criteria, although log likelihood value is larger in Model 2. This is probably because Model 2 uses smaller sample size and a narrower definition of assets.

Subsequently, the RTS function in (4) and the average cost (AC) function in (9) are retrieved using the estimated coefficients, $\alpha, \delta$ and $\theta$. The changes of both functions over throughput (TEU) are depicted in Fig. 1 and Fig. 2, respectively.

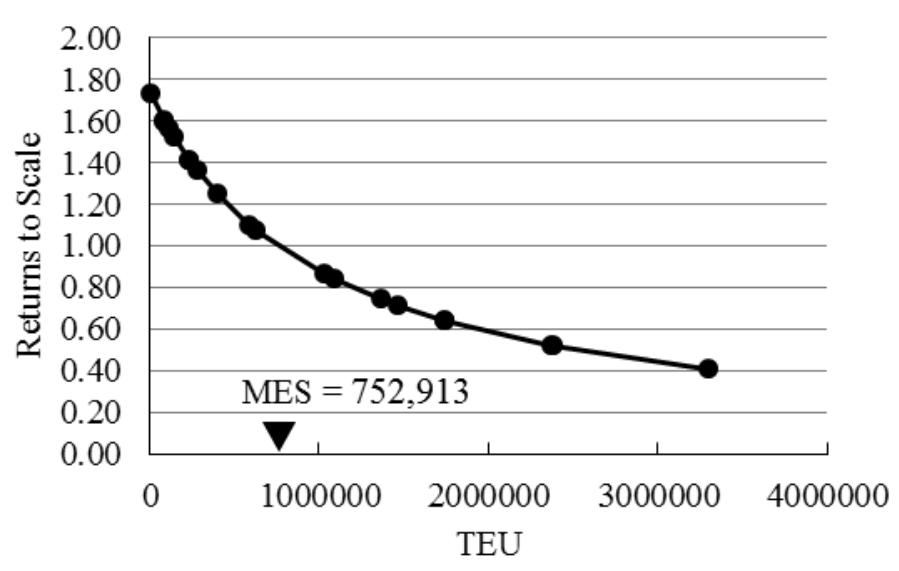

Fig. 1. Returns to scale function and MES of CTOs in South Korea (Model 1).

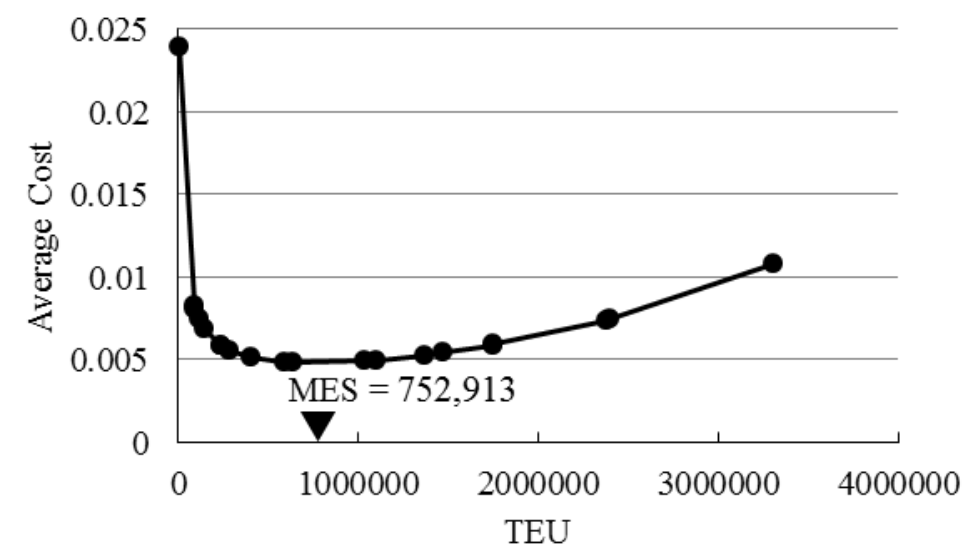

Fig. 2. Average cost function and MES of CTOs in South Korea (Model 1). 
Note: Each dot represents the returns to scale or the average cost of container terminal operators. The constant of integration in (9) is not estimated due to the lack of cost data. Therefore, average costs in y axis do not correspond to the container terminal operators' estimated costs. The value of the MES is calculated as 752,913 TEU using (6). In Fig 1, the value of RTS starts from 1.7418 ( $\alpha$ at $y=0)$, which corresponds to increasing RTS (RTS $>1$ ), and declines as throughput (y) increases. RTS reaches 1 at the MES and eventually goes below 1, showing decreasing RTS. In Fig. 2, average cost function declines quickly to a minimum point, i.e., the MES, and then increases relatively slowly afterwards. This curvature of the average cost function is similar to what was anticipated roughly in Kaselimi et al. (2011). On the other hand, the graphs of the RTS and the AC functions from Model 2 are presented in Fig. 3 and Fig. 4. The estimated MES is 716,898TEU.

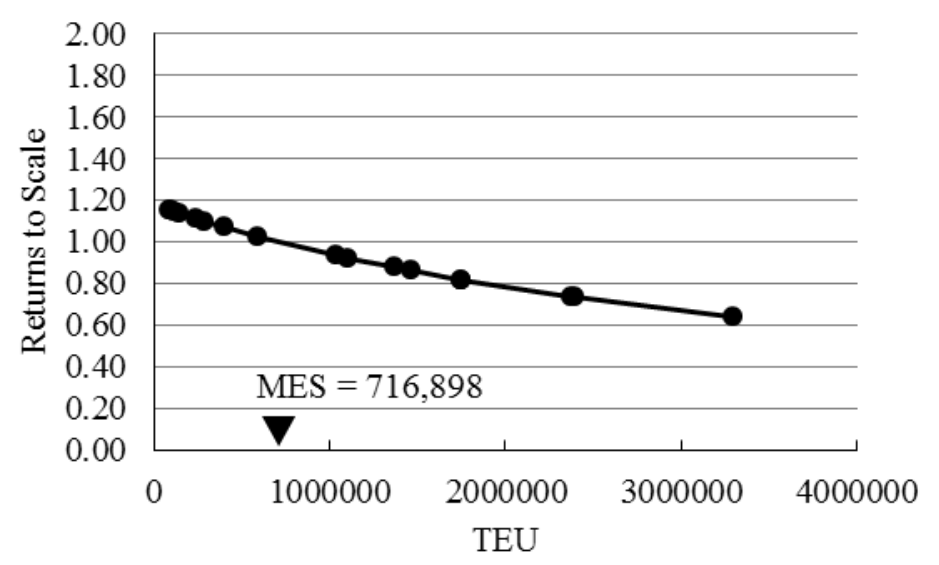

Fig. 3. Returns to scale function and MES of CTOs in South Korea (Model 2).

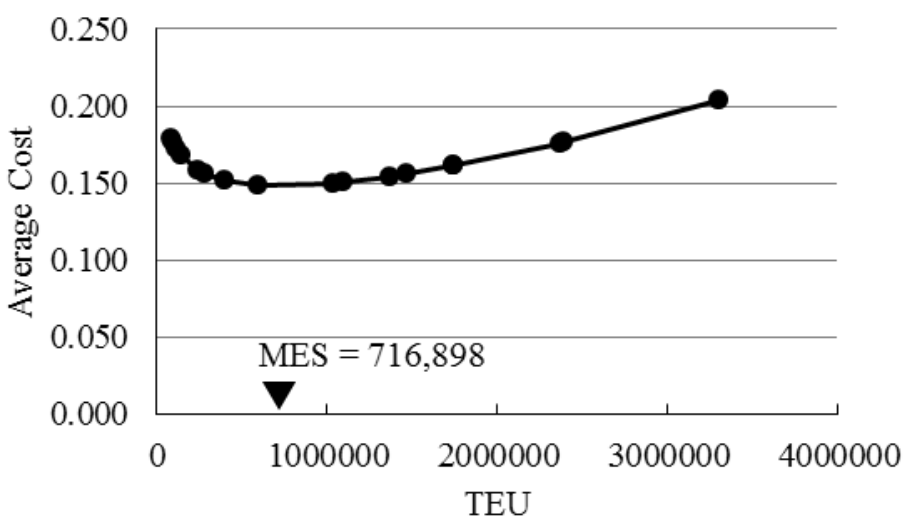

Fig. 4. Average cost function and MES of CTOs in South Korea (Model 2).

Note: Each dot represents the returns to scale or the average cost of container terminal operators. The constant of integration in (9) is not estimated due to the lack of cost data. Therefore, average costs in y axis do not correspond to the container terminal operators' estimated costs. 
The following table summarises whether each individual CTO's throughput lies in the over, under or optimal capacity area. Overcapacity and undercapacity are defined as having throughput larger or smaller than the estimated MES, respectively. Optimal capacity is defined as having throughput within a specified range e.g. 10 or $20 \%$, around the MES.

Table 3

Over, under and optimal capacity of CTOs relative to the estimated MES.

\begin{tabular}{|c|c|c|c|c|c|c|c|}
\hline \multirow[b]{3}{*}{ ID } & \multirow[b]{3}{*}{ TEU } & \multicolumn{3}{|c|}{ Model 1} & \multicolumn{3}{|c|}{ Model 2} \\
\hline & & \multicolumn{3}{|c|}{$\mathrm{MES}=752,913$} & \multicolumn{3}{|c|}{ MES $=716,898$} \\
\hline & & $\mathrm{O} / \mathrm{U}$ & $\begin{array}{c}\text { MES+- } \\
10 \%\end{array}$ & $\begin{array}{c}\text { MES+- } \\
20 \%\end{array}$ & $\mathrm{O} / \mathrm{U}$ & $\begin{array}{c}\text { MES+- } \\
10 \%\end{array}$ & $\begin{array}{c}\text { MES+- } \\
20 \%\end{array}$ \\
\hline 6 & $3,299,457$ & $\mathrm{O}$ & $\mathrm{N}$ & $\mathrm{N}$ & $\mathrm{O}$ & $\mathrm{N}$ & $\mathrm{N}$ \\
\hline 8 & $2,391,890$ & $\mathrm{O}$ & $\mathrm{N}$ & $\mathrm{N}$ & $\mathrm{O}$ & $\mathrm{N}$ & $\mathrm{N}$ \\
\hline 7 & $2,375,614$ & $\mathrm{O}$ & $\mathrm{N}$ & $\mathrm{N}$ & $\mathrm{O}$ & $\mathrm{N}$ & $\mathrm{N}$ \\
\hline 5 & $1,747,307$ & $\mathrm{O}$ & $\mathrm{N}$ & $\mathrm{N}$ & $\mathrm{O}$ & $\mathrm{N}$ & $\mathrm{N}$ \\
\hline 2 & $1,744,861$ & $\mathrm{O}$ & $\mathrm{N}$ & $\mathrm{N}$ & $\mathrm{O}$ & $\mathrm{N}$ & $\mathrm{N}$ \\
\hline 3 & $1,465,206$ & $\mathrm{O}$ & $\mathrm{N}$ & $\mathrm{N}$ & $\mathrm{O}$ & $\mathrm{N}$ & $\mathrm{N}$ \\
\hline 1 & $1,366,534$ & $\mathrm{O}$ & $\mathrm{N}$ & $\mathrm{N}$ & $\mathrm{O}$ & $\mathrm{N}$ & $\mathrm{N}$ \\
\hline 9 & $1,099,366$ & $\mathrm{O}$ & $\mathrm{N}$ & $\mathrm{N}$ & $\mathrm{O}$ & $\mathrm{N}$ & $\mathrm{N}$ \\
\hline 4 & $1,032,732$ & $\mathrm{O}$ & $\mathrm{N}$ & $\mathrm{N}$ & $\mathrm{O}$ & $\mathrm{N}$ & $\mathrm{N}$ \\
\hline 12 & 902,077 & $\mathrm{O}$ & $\mathrm{N}$ & $\mathrm{Y}$ & $\mathrm{O}$ & $\mathrm{N}$ & $\mathrm{N}$ \\
\hline 11 & 747,445 & $\mathrm{U}$ & $\mathrm{Y}$ & $\mathrm{Y}$ & $\mathrm{O}$ & $\mathrm{Y}$ & $\mathrm{Y}$ \\
\hline 10 & 634,916 & $\mathrm{U}$ & $\mathrm{N}$ & $\mathrm{Y}$ & $\mathrm{U}$ & $\mathrm{N}$ & $\mathrm{Y}$ \\
\hline 13 & 592,662 & $\mathrm{U}$ & $\mathrm{N}$ & $\mathrm{N}$ & $\mathrm{U}$ & $\mathrm{N}$ & Y \\
\hline 15 & 400,870 & $\mathrm{U}$ & $\mathrm{N}$ & $\mathrm{N}$ & $\mathrm{U}$ & $\mathrm{N}$ & $\mathrm{N}$ \\
\hline 16 & 285,906 & $\mathrm{U}$ & $\mathrm{N}$ & $\mathrm{N}$ & $\mathrm{U}$ & $\mathrm{N}$ & $\mathrm{N}$ \\
\hline 18 & 239,018 & $\mathrm{U}$ & $\mathrm{N}$ & $\mathrm{N}$ & $\mathrm{U}$ & $\mathrm{N}$ & $\mathrm{N}$ \\
\hline 14 & 237,800 & $\mathrm{U}$ & $\mathrm{N}$ & $\mathrm{N}$ & $\mathrm{U}$ & $\mathrm{N}$ & $\mathrm{N}$ \\
\hline 19 & 145,538 & $\mathrm{U}$ & $\mathrm{N}$ & $\mathrm{N}$ & $\mathrm{U}$ & $\mathrm{N}$ & $\mathrm{N}$ \\
\hline 21 & 114,649 & $\mathrm{U}$ & $\mathrm{N}$ & $\mathrm{N}$ & $\mathrm{U}$ & $\mathrm{N}$ & $\mathrm{N}$ \\
\hline 20 & 93,920 & $\mathrm{U}$ & $\mathrm{N}$ & $\mathrm{N}$ & $\mathrm{U}$ & $\mathrm{N}$ & $\mathrm{N}$ \\
\hline 17 & 85,772 & $\mathrm{U}$ & $\mathrm{N}$ & $\mathrm{N}$ & $\mathrm{U}$ & $\mathrm{N}$ & $\mathrm{N}$ \\
\hline 23 & 63,739 & $\mathrm{U}$ & $\mathrm{N}$ & $\mathrm{N}$ & $\mathrm{U}$ & $\mathrm{N}$ & $\mathrm{N}$ \\
\hline 24 & 28,000 & $\mathrm{U}$ & $\mathrm{N}$ & $\mathrm{N}$ & $\mathrm{U}$ & $\mathrm{N}$ & $\mathrm{N}$ \\
\hline \multirow[t]{2}{*}{22} & 6,451 & $\mathrm{U}$ & $\mathrm{N}$ & $\mathrm{N}$ & $\mathrm{U}$ & $\mathrm{N}$ & $\mathrm{N}$ \\
\hline & & \multicolumn{3}{|c|}{ Over:Under $=10: 14$} & \multicolumn{3}{|c|}{ Over:Under $=11: 13$} \\
\hline
\end{tabular}

Note: ID is the identification number for individual CTOs given in Table 1. 'U' and 'O' indicate a terminal operator's TEU is smaller or larger than the estimated MES. ' $Y$ ' indicates an operator's TEU lies within a specified range of the estimated MES as an indication of optimal capacity. ' $\mathrm{N}$ ' is given if not. Two ranges, MES $\pm 10 \%$ and $\pm 20 \%$, are used to find optimality.

The issue of overcapacity looks relatively modest considering 10 out of 24 (Model 1) or 11 out of 24 (Model 2) have throughput larger than the MES. Conversely, this also means that undercapacity seems a stronger issue in Korean container ports. However, if we focus on the Busan port (from ID 1 to 9), overcapacity issues are ubiquitous in both models. In addition, no 
CTOs in Busan port are within the range of optimal capacity around the MES. Only 3 out of 24 CTO throughputs are within the 20\% range of the MES in both Model 1 and 2.

\section{Concluding Remarks}

Notwithstanding the importance of MES in any industry, extant literature has failed to estimate the MES of the port industry. Although some approaches (see Kaselimi et al. 2011) have been undertaken to seek MES, no single study accurately estimated the MES in the port industry. By adopting Zellner and Revankar (1969) and Zellner and Ryu (1998), this study suggests and applies a new approach to estimate the MES of the port industry with Korean data, which may contribute to providing port policy makers and port planners with insights when they consider reshaping policies pertaining to port competition, port concession, port planning and overcapacity. When they have no confidence in future demands in the near future and need to estimate the proper terminal scale, the results of this study by estimating the MES can offer valuable information.

The results from the calculated value of the MES indicate that 14 (Model 1) or 13 (Model 2) out of 24 CTOs operate in sub-MES scale i.e. their TEU's are smaller than the MES (Model 1). This finding may indicate that an excessive number of CTOs exist in the market, which also increases overcapacity and worsens their cost structure as seen in their negative profits in Table 1. Additionally, Fig. 1 and 2 show that the CTOs' TEUs are widely spread around the estimated MES. That is, their operations are overall far from optimal in terms of the distance of their TEUs from the MES. Also, only three CTOs are within the $20 \%$ range of the MES (Table 3). Most of them are not likely to efficiently operate the terminal, because average costs are relatively high. It implies that CTOs that have small scales undertake the terminal operation with high operating costs. However, it can be argued that overall the port capacity in Busan port may lean towards overcapacity since all of the CTOs in Busan operate at more than $20 \%$ of MES. This finding is consistent with major Korean shipping news that in particular Busan port has encountered overcapacity (Korea Shipping Gazette, 2014). De Langen and Pallis (2006; p. 9) ascertained "an important condition for the viability of intra competition is that the market should be at least twice as large as the MES for providing a port service". In the case of Busan port, their market demand of container throughput in 2013 was approximately $17,686,099 \mathrm{TEU}^{2}$ (KPLA, 2015), which is approximately $25(17,686,099 / 716,898=24.67)$ times that of the MES. This may cause excessive intra competition, since large market size relative to the MES leads to intra-port competition. It is found that the number of CTOs in Korea is increasing, whereas their profits have been decreasing over recent years, causing overcapacity issues. Interestingly, this finding would be similar to Chang et al. (2012)'s findings that the Korean government appeared to have over-invested in recent port developments.

A possible explanation for the above results would be that since 1997 the Korean government has changed the policy from the license system to the registration one when CTOs enter the port market. At the same time, the registration requirement has been significantly alleviated (Korea Shipping Gazette, 2014). As a result, many CTOs could easily enter the market. Then,

\footnotetext{
${ }^{2}$ This is slightly different from the sum of TEU in Busan port in Table 1, since some terminals (e.g. Gamcheon Hanjin terminal: 264TEU, Uam terminal: 514,920TEU, General terminal: 598,215TEU, multi-purpose terminal: $49,734 \mathrm{TEU}$ ) were not included in the analysis due to the lack of data availability (e.g. turnover and profit).
} 
there has been overcapacity. This devastated the existing and new CTOs' profits. Notably, this phenomenon is contrary to the EU case. As an example, until the mid 1990s, EU was likely to be protectionist by awarding new terminals to incumbents when their terminal business was not lucrative and financial condition was weak (Rodrigue et al., 2011). Interestingly, De Langen and Pallis (2007) found that there is only one CTO in almost half the ports they surveyed in the EU. On the other hand, for instance, Busan North port had ten CTOs before the construction of new ports, but over five CTOs entered the port market in the period between 2007 and 2010. It can be argued that the overcapacity issue is not surprising given that there are too many CTOs in one port who are attracting the same customers in similar geographical ranges. Hutchison Korea Terminals, subsidiary of Hong Kong's Hutchison Port Holdings $(\mathrm{HPH})$ suspended the one berth at Gamman terminal, and declared that they would return the berth to the Busan port authority because of overcapacity and financial difficulty, although it has obtained a concession period between 2002 and 2027 (Monthly Maritime Korea, 2013). This phenomenon typically shows that the HPH, whose port operation expertise is the best in the world, also could not manage to deal with overcapacity of Busan port in Korea. As a matter of fact, this issue should be carefully handled by government intervention and new port policy, since there may be no room for implementing strategic movement under such overcapacity. Terada (2002; p. 3) argued that for under/overcapacity issues in ports "government intervention is necessary to correct the market failure and attain the socially optimal quantity of the public service that the facility generates". Economic theories claimed that when an incumbent faces new entrants in the market, it tends to adopt a pre-emptive pricing strategy or to establish excessive capacity so as to defend its market status (Spence, 1977; Eaton and Lipsey, 1977). However, if the entrants have competitive advantage such as better location or technology, then the above actions do not prevent the growth of the entrants (Luo et al., 2012). Interestingly, Busan North ports, which are incumbents, encounter financial difficulty, whilst the profit of Busan New port's CTOs (entrants) seems adequate (see Table 1). The reason for this would be that Busan New port has faster container cargo handling equipment, deeper water depth and better location to accommodate the mega container ships.

Before awarding concession, government or port authorities therefore should try to find a balance between economies of scale and overcapacity so as to make sure economies of scale are passed on to the customers and CTOs earn appropriate profits (Kaselimi et al., 2011). In order to exploit the economies of scale, the Korean government may initiate the integration of CTOs that have not reached the MES as long as their geographical location is in proximity. Central government body (Ministry of Ocean and Fisheries) recognised the need for integration of the CTOs, so it has tried to integrate four CTOs into one at Gamman terminal of Busan North port. Gamman terminal has four berths. It was operated by four CTOs, each of which was in charge of one berth. Further, government policy promotes the integration between Sinsundae terminal and Uam terminal of Busan North port. Once, integration is complete, they operate the combined berths together. It may be interpreted that this integration is a belated effort to mitigate overcapacity on purpose. This promotion of integration was not based on the estimation of the MES. If the government conducted the estimation of the MES in regard to whether awarding one terminal or splitting it into multiple CTOs before allowing too many CTOs to enter this market (Theys et al., 2010), it would avoid the wasteful overcapacity of the port industry in Korea. In terms of port policy, it should not be overlooked that the aim of government and port authorities is to maximise the annual cargo throughput per area so as to shun constructing new terminal capacities until all existing capacities are fully exploited and the level of ship waiting time and berth occupancy is intolerable (Bassan, 2007). It would be plausible that in order to increase port capacity and avoid additional berth construction port planers should concentrate on improving operational productivity by employing re-layouts of 
port facilities and horizontal integration between CTOs (Vis, 2006; Chang et al., 2012). The managers of CTOs also should be aware that setting prices below costs to entice cargoes from other rivals amidst intense intra and inter competition is not an advisable strategy (Haralambides, 2002), because it drives all CTOs towards a zero-sum game.

Prior to concluding this paper, it should be noted that this paper argues that ports (or CTOs) might compete primarily on cost due to the rather substitutable nature of the service when the shipping line chooses the CTO. However, numerous previous studies on port competitiveness and port selection contended that there are a number of other determinants such as physical location, reliability of schedules in port, faster handling operations, inter-modal link, port congestion, port safety, skilled port labour etc (Tongzon and Heng, 2005; Yeo et al., 2008; Chang et al., 2008; Wang et al., 2014; Yang and Chen, 2016). As Kaselimi et al. (2011) stressed that many other factors affect the preferred scaled observed in practice compared to the actual MES, it may be plausible to admit that identifying the MES is only part of the story pertaining to the optimal level of output. Owing to a difficulty in identifying MES which derived from other considerable factors such as different port governance, market size, structure and operational considerations (Kaselimi et al., 2011), in practice, it can be argued that many ports in the world operate with half that level of output and consider themselves easily large enough to be achieving economies of scale.

Despite this study's novelty, it has several limitations. The estimation results show that the amount of throughput is explained by the size of the workforce well. However, the causation may not be uni-directional since the larger throughput could cause more employment. Also, different specifications of the RTS functions could be tested in the future research. On the other hand, non-current or fixed assets are not strongly significant in producing throughput in the results. A couple of reasons could be behind this finding. First, the large amount of non-current or fixed assets does not always guarantee the increase in throughput since they are more closely related to the capacity not actual processing. Thus, the linkage between non-current or fixed assets and throughput seems weaker than normally expected. Second, the accounts of noncurrent and fixed assets in annual reports may not fully reflect the essential assets in container terminal operation. The use of more relevant datasets is recommended for future research. This study has a weakness in terms of generalisation because the data were collected from only Korea. Nonetheless, the main application of this research might be applied to other regions such as China and South-East Asia where overcapacity is getting fierce. Finally, this study only explored the container port industry. Accordingly, future research can investigate the liquid and dry bulk port sector.

\section{Acknowledgements}

The authors express their gratitude to the editor, Prof. José Manuel Vassallo, and anonymous referees for their constructive and insightful comments on this paper.

\section{References}

Ashar, A., 2001. Strategic pricing in newly privatised ports. Maritime Economics \& Logistics $3(1), 52-78$.

Asteris, M., Collins, A., 2010. UK container port investment and competition: impediments to the market. Transport Reviews 30 (2), 163-178. 
Barzdukas, D., Devore, J., Gamble, H., Kopp, J., 2000. Competition and cooperation as trade policy: past lessons and future opportunities for the port of Tacoma and port of Seattle. University of Washington Global Trade, Transportation, and Logistics Studies.

Bassan, S., 2007. Evaluating seaport operation and capacity analysis-preliminary methodology. Maritime Policy \& Management 34 (1), 3-19.

Bottasso, A., Conti, M., Ferrari, C., Merk, O., Tei, A., 2013. The impact of port throughput on local employment: evidence from a panel of European regions. Transport Policy 27, 3238 .

Caves, R.E., Khalilzadeh-Shirazi, J., Porter, M.E., 1975. Scale economies in statistical analyses of market power. The Review of Economics and Statistics 57 (2), 133-140.

Chang, Y.-T., Shin, S.-H., Lee, P.T.-W., 2014. Economic impact of port sectors on South African economy: an input-output analysis. Transport policy 35, 333-340.

Chang, Y.-T., Tongzon, J., Luo, M., Lee, P. T.-W., 2012. Estimation of optimal handling capacity of a container port: an economic approach. Transport Reviews 32 (2), 241-258.

Chang, Y.-T., Lee, S.-Y., Tongzon, J.L., 2008. Port selection factors by shipping lines: different perspectives between trunk liners and feeder service provider. Marine Policy 32 (6), 877-885.

Cory, P.F., 1981. A technique for obtaining improved proxy estimates of minimum optimal scale. The Review of Economics and Statistics 63 (10), 96-106.

De Langen, P.W., Pallis, A.A., 2007. Entry barriers in seaports. Maritime Policy and Management 34 (5), 427-440.

De Langen, P.W., Pallis, A.A., 2006. Analysis of the benefits of intra-port competition. International Journal of Transport Economics 33 (1), 69-85.

De Weille, J., Ray, A., 1974. The optimum port capacity. Journal of Transport Economics and Policy 8 (3), 244-259.

Deng, P., Lu, S., Xiao, H., 2013. Evaluation of the relevance measure between ports and regional economy using structural equation modelling. Transport Policy 27, 123-133.

Eaton, B.C., Lipsey, R.G., 1979. The theory of market pre-emption: the persistence of excess capacity and monopoly in growing spatial markets. Economica 46 (182), 149-158.

Flor, L., Defilippi, E., 2003. Port infrastructure: an access model for the essential facility. Maritime Economics \& Logistics 5 (2), 116-132.

Galhena, R., 2015. Container port overcapacity is bad! The Sunday Leader. http://www.thesundayleader.1k/2015/03/01/container-port-overcapacity-is-bad/

Gardner, B., Marlow, P., Pettit, S., 2006. Full cost recovery in EU ports operating as commercial undertaking. Transport Policy 13, 2-21.

Haralambides, H., 2002. Competition, excess capacity, and the pricing of port infrastructure. International Journal of Maritime Economics 4 (4), 323-347.

Heaver, T.D., 1995. The implications of increased competition among ports for port policy and management. Maritime Policy \& Management 22 (2), 125-133. 
Jansson, J.O., Shneerson, D., 1982. Port Economics. The MIT Press, London.Kaselimi, E.N., Notteboom, T.E., Pallis, A.A., Farrell, S., 2011. Minimum efficient scale (MES) and preferred scale of container terminals. Research in Transportation Economics 32 (1), 71-80.

Korea Shipping Gazette, 2013.

http://www.ksg.co.kr/news/news_print.jsp?bbsID=news\&bbsCategory=KSG\&pNum=88579.

Korea Shipping Gazette, 2014.

http://ksg.co.kr/news/news_view.jsp?bbsID=news\&pNum=96579\&bbsCategory=KSG\&cate goryCode $=\mathrm{RKC}$.

KPLA., 2015. Port handling brochure, Korea Port Logistics Association.

Luo, M., Liu, L., Gao, F., 2012. Post-entry container port capacity expansion. Transportation Research Part B: Methodological 46 (1), 120-038.

Marquardt, D.W., 1963. An algorithm for least-scares estimation of nonlinear parameters. Journal of the Society for Industrial and Applied Mathematics 11 (2), 431-441.

Monthly Maritime Korea, 2013.

http://monthlymaritimekorea.com/news/articleView.html?idxno=12285.

Musso, E., Ferrari, C., Benacchio, M., 1999. On the global optimum size of port terminals. International Journal of Transport Economics 26 (3), 415-437.

OECD., 2004. OECD Territorial Reviews: Busan, Korea. http://www.oecd-

ilibrary.org/urban-rural-and-regional-development/oecd-territorial-reviews-busan-korea2005_9789264007604-en;jsessionid=25c3694ge05j2.x-oecd-live-03.

Park, J.S., Seo, Y.-J., 2016. The impact of seaports on the regional economies in South Korea: panel evidence from the augmented Solow model. Transportation Research Part E: Logistics and Transportation Review 85, 107-119.

Porter, M.E., 1998. Competitive Advantage: Creating and Sustaining Superior Performance. Free Press, New York.

Pratten, C., 1988. A Survey of the Economics of Scale. Commission of the European Communities, Brussels.

Rodrigue, J.-P., Notteboom, T., Pallis, A.A., 2011. The financialization of the port and terminal industry: revisiting risk and embeddedness. Maritime Policy \& Management 38 (2), $1-23$.

Slack, B., 1993. Pawns in the game: ports in a global transportation system. Growth and Change 24 (4), 579-588.

Song, L., van Geenhuizen, M., 2014. Port infrastructure investment and regional economic growth in China: panel evidence in port regions and provinces. Transport Policy 36, 173-183.

Spence, A.M., 1977. Entry, capacity, investment and oligopolistic pricing. The Bell Journal of Economics 8 (2), 534-544.

Terada, H., 2002. An analysis of the overcapacity problem under the decentralized management system of container ports in Japan. Maritime Policy \& Management 29 (1), 315. 
Theys, C., Notteboom, T.E., Pallis, A.A., De Langen, P.W., 2010. The economics behind the awarding of terminals in seaports: Towards a research agenda. Research in Transportation Economics 27 (1), 37-50.

Tongzon, J., Heng, W., 2005. Port privatization, efficiency and competitiveness: some empirical evidence from container ports (terminals). Transportation Research Part A: Policy and Practice 39 (5), 405-424.UNCTAD., 2014. Review of Maritime Transport. Geneva.

Vis, I., 2006. A comparative analysis of storage and retrieval equipment at a container terminal. International Journal of Production Economics 103 (2), 680-693.

Wang, Y., Yeo, G.-T., Ng, A.K.Y., 2014. Choosing optimal bunkering ports for liner shipping companies: a hybrid Fuzzy-Delphi-TOPSIS approach. Transport Policy 35, 358365.Wiegmans, B.W., Konings, R., Priemus, H., 2009. Critical mass for the development of a new container port in Vlissingen. Maritime Economics \& Logistics 11 (4), 399-417.

Yang, Y.-C., Chen, S.-L., 2016. Determinants of global logistics hub ports: comparison of the port development policies of Taiwan, Korea, and Japan. Transport Policy 45, 179-189.

Yeo, G.-T., Roe, M., Dinwoodie, J., 2008. Evaluating the competitiveness of container ports in Korea and China 42 (6), 910-921.

Zellner, A., Revankar, N.S., 1969. Generalized production functions. The Review of Economic Studies 36 (2), 241-250.

Zellner, A., Ryu, H., 1998. Alternative functional forms for production, cost and returns to scale function. Journal of Applied Econometrics, 13, 101-127. 